\title{
DIGRESIONES EN TORNO A LAS MEDIDAS PROVI- SIONALES POR DEMANDA DE NULIDAD, SEPARA- CION Y DIVORCIO
}

LUis FERNANDO SAURA

Profesor Titular de Derecho Civil 

No obstante el transcurso de tres años desde la modificación del Código Civil en materia matrimonial, existen todavía parcelas en la nueva normativa que exigen una mayor depuración, un mayor rigor interpretativo.

$Y$ el problema se complica si tenemos en cuenta que las modificaciones de referencia introdujeron una serie de procedimientos específicos, cuya vigencia respeta la recién promulgada reforma de la Ley de Enjuiciamiento Civil.

Sería conveniente pues, en este orden de cosas, llamar la atención sobre los artículos 102 a 106 del Código Civil, habida cuenta que la práctica forense los viene interpretando y aplicando, pensamos, con cierto esquematismo y ligereza. Buen ejemplo de ello pueden ser los extremos que pasamos a analizar sucintamente:

1. Tal vez el artículo más desaprovechado de los enunciados líneas atrás, y que es, sin embargo, una especie de comodín de todos los del capítulo, sea el 102, y más concretamente el párrafo final del mismo.

Dispone el número $2 .^{\circ}$ del referido artículo: "Quedan revocados los consentimientos y poderes que cualquiera de los cónyuges hubiera otorgado al otro".

Desaprovechado, entonces, porque si bien su efecto se produce «ipso iure" desde el momento mismo de la admisión de la demanda de nulidad, separación o divorcio, su efectividad real no se suele llevar a sus últimas consecuencias mediante el uso adecuado y oportuno de los medios aseguratorios que establece el párrafo final del propio artículo, al manifestar: "A estos efectos, cualquiera de las partes podrá instar la oportuna anotación en el Registro Civil y, en su caso, en los de la Propiedad y Mercantil».

Contrariamente a lo que acaece respecto del ejercicio de otros tipos de acciones, lo usual hasta el momento en los procesos sobre nulidad, separación y divorcio es no usar de esta ventaja que ofrece la ley. Ventaja que tiende al aseguramiento de los derechos del cónyuge demandante, impidiendo, de forma eficaz, la validez frente a terceros de los actos que pueda realizar el demandado en fraude de su consorte, o, simplemente, con extralimitación de sus facultades de administración o de disposición.

La única explicación lógica a esta habitual omisión sea la que se deriva del entendimiento literal de la denominación de las medidas como provisionales, sin caer en la cuenta de que, empero su nombre, las mismas pueden extender su vigencia luengamente, si atendemos a la posibilidad de apelación de la sentencia recaída en la pieza principal del proceso. 
Ciertamente, se puede argüir que tal como está regulado actualmente en el Código Civil lo relativo al régimen económico matrimonial, y más especiíficamente la sociedad de gananciales, con su exigencia del consentimiento de ambos cónyuges para actos de disposición e incluso de administración, no parece posible - salvo, naturalmente, en el supuesto, frecuente por otra parte, del poder extenso especial concedido por un cónyuge al otro- el acto dispositivo fraudulento o meramente carente del consentimiento de una de ellos, al menos en orden al acceso de dicho acto al Registro de la Propiedad tratándose de bienes inmuebles. Mas, ocurre, que la posibilidad de realización de actos de disposición respecto de muebles y valores es factible sin el consentimiento del cónyuge, no sólo por la propia naturaleza de tales cosas y su distinta regulación legal, sino porque el propio Código lo permite en algunos casos, como, por ejemplo, en los artículos 1384 y 1385.

Pero cuando deviene imprescindible la anotación de la demanda de nulidad, separación o divorciọ, es en-el caso del cónyuge del comerciante. En efecto, los consentimientos contemplados en los artículos 7, 8 y 9 del Código de Comercio, exigen la anotación de su revocación en el Registro Mercantil para que la misma produzcan efectos frente a terceros.

Otro tema es el relativo a la eficacia frente a terceros de la anotación preventiva de la demanda de nulidad, separación o divorcio únicamente en el Registro Civil. Problema que puede ser objeto de otro estudio, bastando, por ahora, apuntar que a la vista del artículo 11 del Código de Comercio, en lo que se refiere a comerciantes, su eficacia será muy relativa, por no decir nula.

2. Cuestión, asimismo, de interés es la relativa a la distinción y co- . rrecta aplicación de las denominadas, respectivamente, medidas provisionalísimas y provisionales, y, especialmente, en orden a la subsistencia de aquéllas una vez inciado el proceso principal.

A este respecto, dispone el artículo 104 del Código Civil: «El cónyuge que se proponga demandar la nulidad, separación o divorcio de su matrimonio puede solicitar los efectos y medidas a que se refieren los dos artículos anteriores. Estos efectos y medidas sólo subsistirán si dentro de los treinta días siguientes a contar desde que fueron inicialmente adoptados, se presenta la demanda ante el Juez o Tribunal competente».

De la redacción del artículo de referencia se desprende, de manera paladina, la subsistencia de las medidas adoptadas con carácter provisionalísimo, con tal que dentro de los treinta días siguientes a su adopción judicial - prorrogables por otros treinta mediante aplicación del artículo 
1885 de la Ley de Enjuiciamiento Civil- se deduzca la oportuna demanda ante el Juez competente.

Sin perjuicio de alabar, de una parte, la oportunidad del precepto en tanto confirma la posibilidad de adopción urgente de medidas tendentes a paliar o resolver situaciones de grave perentoriedad, es de criticar, sin embargo, en tanto consagra la permanencia de las medidas adoptadas a lo largo de todo el proceso.

El problema surge, a nuestro entender, de la intención del legislador del 1981 de reproducir el espíritu de los artículos 67 del Código Civil en su redacción anterior y del 1885 de la Ley de Enjuiciamiento Civil, pero sin tener en cuenta los artículos 68 del propio Código en su antigua redacción y el 1886 y siguientes de la Ley procesal civil.

Acontece que el legislador, en la Disposición Adicional $4 .^{a}$ de la Ley de 7 de julio de 1981, establece para adopción de las medidas, en los supuestos del artículo 104, el procedimiento establecido en los artículos 1884, 1885 y concordantes de la Ley de Enjuiciamiento Civil, pero resulta que ni tales artículos ni los concordantes establecen, en rigor de verdad, procedimiento alguno. De ello se deriva que el Juez, hoy, de atenerse a la literalidad de los citados preceptos, habrá de tomar decisiones de la mayor importancia sin la más mínima posibilidad de formar su juicio mediante un cauce procesal siquiera elemental o rudimentario.

$Y$ ocurre, entonces, que las medidas adoptadas con este carácter de urgencia y sin un procedimiento contradictorio adecuado, pueden no sólo susbistir a lo largo de todo el proceso de nulidad, separación o divorcio, sino, incluso, ser ratificadas en la sentencia dictada en el procedimiento principal.

Esto, en efecto, es lo que está acaeciendo en la práctica forense. Cuando se interesan las medidas referidas en los artículos 102 y 103 por la vía del 104, se dan por vigentes, usualmente, a la hora de la presentación de la demanda principal —salvo el caso, lógicamente, que las medidas dictadas en aquella ocasión no fueran de gusto de la parte actora, en cuyo supuesto no es infrecuente la postulación de la oportuna modificación, por medio de otrosi en el propio escrito de demanda-

Indudablemente, en el supuesto de tenerse por la actora por supuestas y subsistentes las medidas adoptadas previamente, incumbirá a la demandada, si a su interés conviniere, interesar la adopción de otras nuevas en modificación de las anteriores, en el escrito de contestación a la demanda.

En esta tesitura, la interpretación que parece más acertada - ya defen- 
dida por nosotros - ${ }^{1}$ es la que señala el legislador cuando, en la Disposición Adicional 4. ${ }^{a}$ de la Ley de 7 de julio de 1981, remite a las vías procesales respectivas, a saber: respecto de las provisionalísimas la de los artículos 1884 y 1885 de la Ley de Enjuiciamiento Civil; las referidas en el artículo 103 por la del 1896 y siguientes de dicha ley procesal.

Conviene resaltar el artículo 1886 de la Ley de Enjuiciamiento Civil, luminosamente aclaratorio del problema. Dice el mismo: «Interpuesta y admitida la demanda o querella, el Juez adoptará durante la sustanciación del proceso, y mientras éste perdure, las medidas enunciadas en los artículos siguientes».

No sería tampoco oportuno concluir el comentario al punto que nos ocupa, sin hacer una brevísima referencia a los artículos 1881 y 1885 de la Ley de Enjuiciamiento Civil, tal cual han quedado redactados por la Ley 34/84, y así:

a) De interpretarse los mismos en su estricta literalidad, se llegaría a la conclusión de que únicamente la mujer casada podría interesar la adopción de las medidas provisionalísimas, mientras que al marido se le veda radicalmente la posibilidad de su postulación. Conclusión abiertamente contradictoria de lo dispuesto en el artículo 104 del Código Civil, y, aún peor, conculcatoria del artículo 14 de la Constitución.

b) Las únicas innovaciones introducidas en los artículos 1881 y 1885 consisten en la supresión de la referencia a la "querella por amancebamiento" y la adición de la palabra "divorcio", modificaciones sin duda oportunas en cuanto actualizadoras, pero que ponen de manifiesto la ligereza incomprensible con la que el legislador de 1984 ha tratado tales artículos.

3. Dispone el párrafo primero del artículo 106: "Los efectos y medidas previstos en este capítulo terminan, en todo caso, cuando sean sustituidos por los de la sentencia estimatoria o se ponga fin al procedimiento de otro modo".

En pura ortodoxia interpretativa de los pertinentes preceptos del Código Civil, en armonía con lo dispuesto en las Disposiciones $4 .^{a}$ y $5 .^{a}$ de la Ley 30/81 y los correspondientes de la Ley de Enjuiciamiento Civil, resulta que el proceso matrimonial en orden a nulidad, separación y divorcio, discurre por dos cauces perfectamente nítidos y diferenciados: el procedimiento principal dirigido sólo a manifestar y demostrar si existe o no causa de nulidad, separación o divorcio y en el que, en principio, debe hacerse abstracción de toda cuestión económica; el procedimiento relativo a adopción de las medidas económicas, con carácter transitorio y provisional hasta tanto recaiga 
sentencia firme en el proceso principal, en cuyo caso y, en rigor de verdad, en ejecución de la sentencia dictada en éste habrán de establecerse los efectos definitivos de la nulidad, separación o divorcio declarados.

Planteada de esta suerte la problemática puede acaecer, y no es ello nada infrecuente, que las medidas provisionales adoptadas en el incidente relativo a ellas no hayan adquirido firmeza por haber usado alguna de las partes del procedimiento establecido en el artículo 1900 de la Ley de Enjuiciamiento Civil, habiéndose apelado el Auto recaído en el mismo y hallándose sustanciándose la apelación, empero haber recaído sentencia en la pieza principal y ser ésta firme por no haberse planteado recurso contra la misma. Complicándose todavía más el caso cuando, y esto también ocurre, en la sentencia recaída en la pieza principal existe pronunciamiento en relación con las medidas provisionales, ratificándolas.

En estos supuestos parece clara la aplicación automática del artículo 106 del Código Civil, habida cuenta que, por la ratificación, han sido confirmados los efectos y medidas adoptados provisionalmente, pero ¿qué ocurre con la apelación interpuesta contra el Auto resolutorio del incidente de impugnación de las medidas provisonales?

Indudablemente, la aplicación rigurosa del artículo 106 cegaría el cauce apelatorio, haciéndolo de imposible continuación, provocando su enervación en el estado procesal en que se hallare sin posibilidad alguna de dar lugar a que recayera sentencia en el mismo, entre otras razones porque bien pudiera acaecer que dicha sentencia fuera revocatoria del Auto que, por otra vía, fue confirmado y ratificado en la sentencia principal.

Pero es indudable, asimismo, que la interpretación del artículo 106 cegadora de cauces e imprimiento firmezas, conculca radicalmente el derecho de una de las partes en el proceso, produciendo su indefensión y privándole de una serie de medios y remedios que, de otra parte, le ofrece la propia ley.

En este encrucijada, pues, no cabe, a nuestro juicio, otra postura que no sea la observancia estricta de los dos procedimientos establecidos, manteniéndolos paralelamente, pero con total diferenciación, procediendo a su refundición una vez producidas todas las firmezas y partiendo de éstas para los pronunciamientos definitivos mediante ejecución de la sentencia recaída en el procedimiento principal.

4. Profundizando más en lo referido en el punto anterior en torno a la necesidad de fijación, en la sentencia recaída en el procedimiento principal, de los efectos definitivos de la separación o divorcio declarados, conviene analizar, también someramente, la interesante cuestión relativa a la procedencia de postular, desglosadamente, en la pieza incidental sobre medidas 
provisionales, la fijación de una cantidad para alimentos y otra en concepto de pensión para el cónyuge al que la separación o el divorcio produzca desequilibrio en su situación anterior constante matrimonio.

Evidentemente, ni el inciso primero del número $3 .^{\circ}$ del artículo $103 \mathrm{del}$ Código Civil, ni el 97 del propio cuerpo legal permiten esta interpretación diferenciadora. Dice, en efecto, el artículo 103 que el Juez fijará la contribución de cada cónyuge a las cargas del matrimonio, y esta frase, cargas del matrimonio, supone una conceptuación genérica y englobadora de todas las partidas económicas que han de tenerse por tales, y comprensiva tanto de los alimentos como de la pensión, si bien de forma aglutinada e indisçriminada. $O$, incluso, interpretado de otra manera, no comprende más que la cantidad precisa, a juicio del Juez, para levantar las cargas familiares durante el periodo transitorio hasta tanto recaiga sentencia definitiva en la pieza principal.

Del propio modo, la lectura del párrafo $1 .^{\circ}$ del artículo 97 no admite otra explicación que no sea la referida a una situación ya dada, a partir de cuyo instante han de iniciarse sus efectos.

No obstante la claridad de los citados preceptos, viene al caso el presente comentario en cuanto no es infrecuente que, en el propio escrito interesando las medidas provisionales, se postule ya la fijación de cantidades en el dobley desglosado concepto de una determinada para alimentos y otra en el de pensión para el cónyuge más necesitado y perjudicado, económicamente, por la separación o el divorcio.

Ahora bien, si desde una perspectiva de interpretación rigurosa es, acaso, práctica viciosa, pudiera ser disculpable en algunos casos, en atención a la agilidad y eficacia que puede ofrecer en ellos, pues que, con ganarse en rapidez y despejarse prontamente una incógnita que pueda pesar muy negativamente en las relaciones familiares y personales de los litigantes, no se conculca el derecho de ninguno de ellos pues, como venimos manteniendo, el proceso eminentemente económico ha de ser siempre el de las medidas provisionales, mientras que el principal debe limitarse a declarar si existe o no causa de separación o divorcio.

Existe, sin embargo, un argumento de gravedad insuperable para el supuesto de regirse el matrimonio por el régimen de gananciales o por el de participación en las ganancias. En cualquiera de estos casos, habría que esperar - para conocer con la suficiente exactitud y señalar, condignamente, con justeza la pensión correspondiente- a la liquidación del régimen económico conyugal, antes de cuyo momento no será posible saber el desequili- 
brio económico que la separación o el divorcio pueda producir entre los cónyuges.

1 L. F. SAURA MARTINEZ, «De los efectos y medidas provisionalísimos en la Ley 30/81». Justicia. Barcelona 1982. Pp. 70 y ss. 